\title{
Forecast about energy behavior and the indoor quality of a tower of social dwellings in Bucaramanga (Colombia)
}

\author{
G. Osma, R. Mantilla, M. Millán \& G. Ordóñez \\ Industrial University of Santander, Colombia
}

\begin{abstract}
This paper presents the forecast about the energy behavior and indoor quality of a tower with thirty apartments in Bucaramanga (Colombia) using building simulation tools. The modeling of the tower is done in three tools in order to reduce the error of estimations. This dwelling project is part of a Colombian government program for reducing the lack of dwellings in the social-economics stratum of lowincome families. These dwellings are built in urban zones, they have total areas of between $40 \mathrm{~m}^{2}$ and $60 \mathrm{~m}^{2}$ on one or two levels and their cost is lower than USD 40,000 . The energy sustainability of building depends mainly on passive solutions (daylighting and natural ventilation), although this consideration is very discrete in the architectural design of these social projects. Due to lack of land, many future projects will be built in towers of five levels. In order to estimate the life quality of users in these new kinds of dwellings, the Universidad Industrial de Santander has started an evaluation process of these towers according to the specific climate conditions of Bucaramanga. The building simulation tools used in this study are DesignBuilder, eQUEST and Ecotect for carrying out analyses like potential daylighting, thermal comfort and annual energy consumption. Results indicate that near to $70 \%$ of time (more of 6,000 hours per year) there are no conditions of thermal comfort and the inside temperature is at least $2^{\circ} \mathrm{C}$ above ambient temperature, mainly during tropical sun-time (6 a.m. to 6 p.m.), which is significant, considering the warm and humid climate of the city. Annual energy consumption estimated by DesignBuilder, eQUEST and ECOTECT is very similar: $31.10,28.69$ and $31.95 \mathrm{kWh} / \mathrm{m}^{2} /$ year, respectively. The illumination causes near to $20 \%$ of the total consumption.

Keywords: E Energy simulation, social dwellings, tropical zone, thermal comfort, DesignBuilder, eQUEST, Ecotect analysis.
\end{abstract}




\section{Introduction}

Currently, the environmental impacts caused by buildings are under study, especially those related with using raw material for construction, the consumption of natural resources as freshwater and fossil fuels, energy consumption, and emissions (mainly $\mathrm{CO}_{2}$ ) [1].

Often, the causes of the excessive energy consumption in buildings cannot be determined by a superficial survey, and for that, rigorous analysis should be done about energy requirements, operation and desired conditions in the building. Therefore, the research about energy analysis and reduction of energy consumption in building is growing.

The energy efficient buildings are those that improve the relation between the benefit with respect to the required energy. That is possible from of the implementation of several strategies; whose impact depends on energy demand, operation conditions and climate.

A green energy design ensures is aimed to achieve the rational use of energy, for which, the building could get spaces naturally ventilated and lighted, mitigating the use of HVAC and artificial illumination respectively, and of this way, reducing the energy consumption and the financial cost by operation [2].

Most of these buildings are analyzed by an energy simulation computational tool, which is a high level support for the decision making process [3]. The development of these tools has been intensified since 2000. Energy simulation tools are a strategy widely used in scientific publications, where their usefulness is shown for understanding both the general energy performance of the buildings and particular energy applications. Also, they allow determining the micro-climate conditions and to predict the comfort level of the user during daily, monthly and annual time.

In general, these tools have interfaces with architectural setting and use of detailed mathematical models. For which, they demand large quantity of information as climate conditions, distribution of spaces, materials, mode of use of equipment by occupation and other technical specifications.

The energy analysis process by simulation tools address with the creation of the geometric, constructive and operational model of both the building and the systems; subsequently, the simulations are defined; finally, the analysis of results is carried out [4], from which it is possible to make an evaluation. Due the complexity of the process, specialized personal and equipment with specific characteristics (i.e. RAM memory and graphic capacity) are required.

In Colombia, the use of these tools is lacking, to exception the some private projects. The main cause of that is the generalized ignorance about these tools. Other causes are the shortage of trained personnel and no interest from companies due to increase complexity and cost of the design stage by personnel, licenses and equipment.

Taking into account this lack, the Research Group in Power System (GISEL in Spanish) of the Industrial University of Santander (Colombia) has started a research process related with the potential applicability of energy simulation tools for conducting the energy analysis of several kinds of buildings in tropical zones. 
This is being carried out for Colombian northeast zone, in order to boost improvements in the energy design of buildings in the medium-term.

The GISEL are researching the energy performance and energy design of dwellings because the Colombian government has defined several goals for reducing the lack of dwellings, especially in the social stratum of low-income families, where the solutions are the social dwellings (viviendas de interés social - VIS in Spanish). All of these new dwellings will demand a significant quantity of energy. Currently, this sector is responsible for $25,000 \mathrm{GWh}, 40 \%$ of the energy demand in Colombia.

According to Law 1450 of 2011 of Colombia (Art. 117), a VIS is defined as a habitable unit that fulfills with standards of urban, architectural and of construction design, and whose value does not exceed 135 monthly minimum wages, approximately USD 40,000. These dwellings must have at least three independent, useful and structural areas; in addition, the design and construction must be lined up with the sustainable development [2], although with the last part, it is not clear how this must be done. The area varies mostly between $40 \mathrm{~m}^{2}$ and $60 \mathrm{~m}^{2}$.

In particular, this work aims to the identification and the selection the energy simulation tools that researchers might use for analyzing and supporting the energy design of VIS in Colombia, especially about visual and thermal comfort.

Initially, the paper presents the selection of three energy simulation tools research methodology (Section 2). Subsequently, the modeling (Section 3) and simulations are shown according to specific residential project (Section 4). Finally, the conclusions (Section 5) are presented.

\section{Selection of an energy simulation computation tool}

In order to select a tool to carry out energy analysis of a specific kind of building in particular conditions, a methodology was established in three stages: identification of existing simulation tools, pre-selection of tools according to the interest energy analysis, and evaluation by established factors and selection of tools.

\subsection{Identification of energy building simulation tools}

The identification stage is based on the construction of a directory of simulation tools which characterized them according to cost, computational requirements, application fields, limitations, description and kind of energy analysis.

The directory was built from the specialized directory of US DOE, where in 2010 more than 380 tools were identified [5]. The exhaustive search of scientific publications was done in databases like IBPSA and ELSEVIER; in total, almost 200 papers were reviewed. Currently, the directory collects near to 500 and it is updated to 2014. The directory is shown in [6].

\subsection{Pre-selection of simulation tools}

According to the specific energy analysis that it is necessary to conduct, a first set of tools can be chosen. In this case, a general energy analysis is desired; as a result, 46 tools were obtained that satisfied the requirement. 
To guide the search towards the energy analysis of residential buildings, two factors were considered: background in this field and validity. This was done in accordance with the scientific publications. As result, six tools were preselected: DesignBuilder, DOE-2, Ecotect Analysis, EnergyPlus, eQUEST and ESP-r. Although TRNSYS is a powerful tool, this was not selected because it does not have an architectural interface.

\subsection{Evaluation tools by factors}

The factors are explained in Table 1. The seven factors were established from the requirements identified according to the experience of the research group and relevant aspects found in scientific publications.

Table 1: Evaluation factors.

\begin{tabular}{|c|l|}
\hline Factor & \multicolumn{1}{|c|}{ Description } \\
\hline A & $\begin{array}{l}\text { The tool allows the use of DWG planes, which facilitates the creation of Building } \\
\text { Information Modeling - BIM. }\end{array}$ \\
\hline B & $\begin{array}{l}\text { The tool has an interface clear and orderly, which facilitates the learning process and } \\
\text { simulations. }\end{array}$ \\
\hline C & $\begin{array}{l}\text { Applicability of the tool for environmental conditions of the tropical zone according to } \\
\text { scientific publications. }\end{array}$ \\
\hline D & Representativeness of use according to scientific publications. \\
\hline E & Help information about use of the tool as manuals, tutorials, blogs, etc. \\
\hline F & Use of default values in the interface and ease of changing these values. \\
\hline G & Use of climate file based in real data. \\
\hline
\end{tabular}

In order to assess the tools, each factor can take a value between 1 and 5 , as is indicated tables 2, 3 and 4 .

Table 2: Assessment of the factor $\mathrm{C}$.

\begin{tabular}{|c|c|}
\hline Score & Description \\
\hline 1 & No studies are found in tropical environments. \\
\hline 5 & Evidenced at least one study. \\
\hline
\end{tabular}

Table 3: Assessment of the factors A, B, E, F and G.

\begin{tabular}{|c|c|}
\hline Score & Description \\
\hline 1 & There is no evidence or the factor has a very low level. \\
\hline 5 & To fulfill or the tool has the factor in a high level. \\
\hline
\end{tabular}

Table 4: Assessment of the factor D.

\begin{tabular}{|c|c|}
\hline Score & Description \\
\hline 1 & Evidenced between 0 and 9 times in consulted publications. \\
\hline 2 & Evidenced between 10 and 19 times in consulted publications. \\
\hline 3 & Evidenced between 20 and 29 times in consulted publications. \\
\hline 4 & Evidenced between 30 and 39 times in consulted publications. \\
\hline 5 & Evidenced more than 40 times. \\
\hline
\end{tabular}

The assessment process was done based on the information contained in the directory, scientific publications and website of each tool. Table 5 shows the results. 
Table 5: Result of evaluation.

\begin{tabular}{|c|c|c|c|c|c|c|}
\hline Factor & EnergyPlus & DOE-2 & eQUEST & DesignBuilder & ESP-r & Ecotect \\
\hline A & 5 & 2 & 5 & 5 & 5 & 5 \\
\hline B & 2 & 2 & 5 & 5 & 1 & 5 \\
\hline C & 5 & 1 & 5 & 5 & 1 & 5 \\
\hline D & 5 & 2 & 2 & 1 & 1 & 1 \\
\hline E & 5 & 4 & 5 & 5 & 5 & 5 \\
\hline F & 4 & 5 & 5 & 5 & 5 & 5 \\
\hline G & 5 & 2 & 5 & 5 & 1 & 5 \\
\hline Total & $\mathbf{3 1}$ & $\mathbf{1 8}$ & $\mathbf{3 2}$ & $\mathbf{3 1}$ & $\mathbf{1 9}$ & $\mathbf{3 1}$ \\
\hline
\end{tabular}

According to the result of the assessment, eQUEST, DesignBuilder and Ecotect analysis were selected for carrying out the energy analysis in the VIS. EnergyPlus was not included since DesignBuilder is based on this, in addition, it is friendly.

\section{Modeling}

In this section, the process of modeling, simulation and analysis of results is described for the three tools. This process aims to analyze the useful of each tool according to characteristic of a VIS. The information about VIS was consulted in two official websites, (i) the public procurement (Sistema Electrónico de Contratación Pública) [7] and (ii) the public institute of social dwelling (Instituto de Vivienda de Interés Social y Reforma Urbana del Municipio de Bucaramanga - INVISBU) [8].

\subsection{Description of the selected VIS}

The selected building is one of the 14 multifamily tower of project called Altos de Betania, located on north of city of Bucaramanga, whose geographic location is $7^{\circ} 9^{\prime} \mathrm{N}$ latitude and $73^{\circ} 8^{\prime} \mathrm{W}$ longitude and with an altitude of 656 meters above sea level. Each tower has 30 apartments VIS, 6 per floor. The total project will be finished during 2015.

The multifamily option was chosen over single-family project due to scarcity of suitable lands for the construction of dwellings in the region. For that, the local government has opted for projects of high population density.

Each apartment has an area of $42 \mathrm{~m}^{2}$ for 4 or 5 people; it has living room, two bedrooms, one bathroom and one balcony.

The area of building for every floor is $252 \mathrm{~m}^{2}$, the circulation area and stairs demand $35 \mathrm{~m}^{2}$, and the total area is $287 \mathrm{~m}^{2}$ per floor. The building has a total area of $1,435 \mathrm{~m}^{2}$.

The outer walls are made in masonry with fired clay brick of $25 \mathrm{~cm}$ x $6.5 \mathrm{~cm} \mathrm{x}$ $12 \mathrm{~cm}$. There are two kind of inside walls, the first is seismic concrete wall of 10 $\mathrm{cm}$ of thickness of 3,000 psi, and the second is in masonry with perforated fired clay brick of $10 \mathrm{~cm}$ of thickness.

The front door is metal; the bathroom and the kitchen have ceramic; the windows and the balcony door are metal with colorless glass of $4 \mathrm{~mm}$. There are three windows of $1.4 \mathrm{~m}^{2}, 1.6 \mathrm{~m}^{2}$ and $2.6 \mathrm{~m}^{2}$. The slabs between floors are made in 
concrete of 3,000 psi with structural reinforcement, over that is located a concrete mortar of $5 \mathrm{~cm}$. With respect to the electrical installed capacity, Table 6 shows the related information.

Table 6: Characteristics of illumination and appliances.

\begin{tabular}{|c|c|c|c|}
\hline Element & Quantity per apartment & Power (W) & Total power (W) \\
\hline Computer & 1 & 150 & 150 \\
\hline Fridge & 1 & 300 & 300 \\
\hline TV & 1 & 150 & 150 \\
\hline CFL & 7 & 25 & 175 \\
\hline Wall lamp & 1 & 25 & 25 \\
\hline Incandescent lamp & 1 (stairs) & 54 & 54 \\
\hline
\end{tabular}

\subsection{Modeling of building}

To make the virtual model of the building, initially the geometric model of the structure is developed; later the detailed information is supplied as activities of the users, construction material and energy properties, among others.

The geometric model in Designbuilder was done from importing drawings in 2D in DFX. The render of the building is presented in Fig. 2.

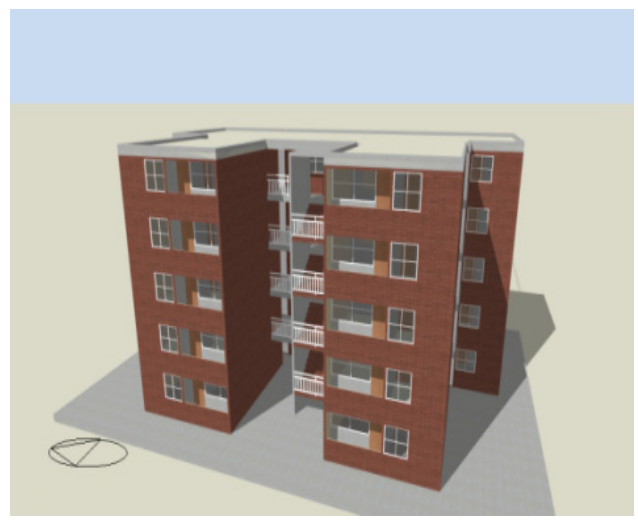

Figure 1: Model of the building in DesignBuilder.

The modeling process with eQUEST is easier than in DesignBuilder, due to the fact that the interface is more intuitive and the quantity of required information is lower. The render of the building is presented in Fig. 2.

Due to the interface of Autodesk Ecotect Analysis is complex, Autodesk Revit Architecture 11 was selected for making the 3D model of the building, where it is possible to import the model because the files are saved in format gbXML. The model was built by thermal zones since that allows us to do the most quantity of simulations, which is possible to know easier the capabilities of the tool. Fig. 3 presents the render of the building. 


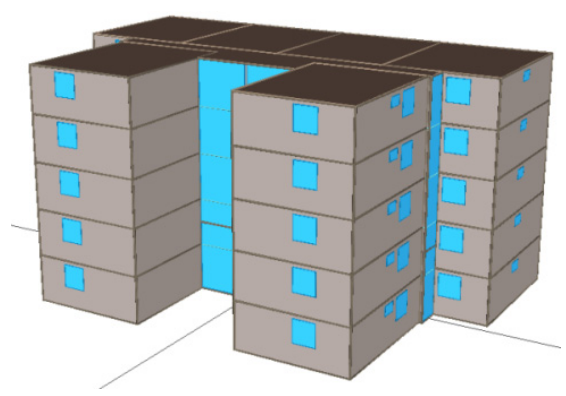

Figure 2: Model of the building in eQUEST.

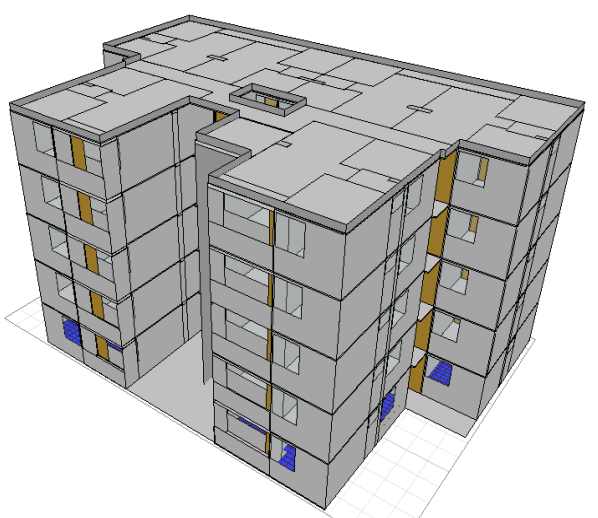

Figure 3: Model of the building in Autodesk Ecotect Analysis.

\section{Simulation and results}

Since three tools have been selected, it is now necessary to know the performance characteristics. For that, the energy analysis of the building was based on three energy factors: thermal comfort, visual comfort and energy consumption. It was that these simulations provided enough information about the energy performance of this type of building in Colombia. Although these three tools aim to conduct the energy analysis of buildings, each one carries out this analysis in a specific way.

\subsection{Thermal comfort}

The results are shown about the thermal comfort according to simulations in Designbuilder and Ecotect Analysis. Fig. 4 shows the average maximum monthly temperature in the apartments obtained by Designbuilder, which is between $20^{\circ} \mathrm{C}$ and $30^{\circ} \mathrm{C}$. The thermal performance of the building and ambient temperature are the main causes for which discomfort is presented.

The time where the thermal comfort is not obtained can be measured as a function of the quantity of hours during a year where the inside temperature 
overtakes a specific value. If this value is $24^{\circ} \mathrm{C}$, the discomfort will represent $80 \%$ of time (7,008 hours per year), and it will be $35 \%(3,066$ hours per year) if the reference value is $26^{\circ} \mathrm{C}$.

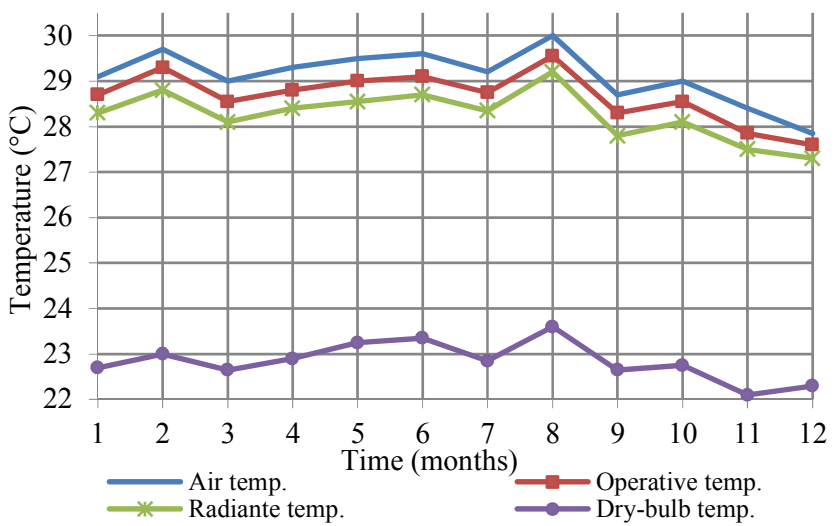

Figure 4: Maximum temperature of building calculated in DesignBuilder.

Now, considering the Ecotect simulations with $24^{\circ} \mathrm{C}$ as a reference temperature, the time of thermal discomfort will occur $67 \%$ of the time $(5,872$ hours per year), such as Fig. 5 indicates. This difference in the results between these tools may be due to the particular approach in the natural ventilation.

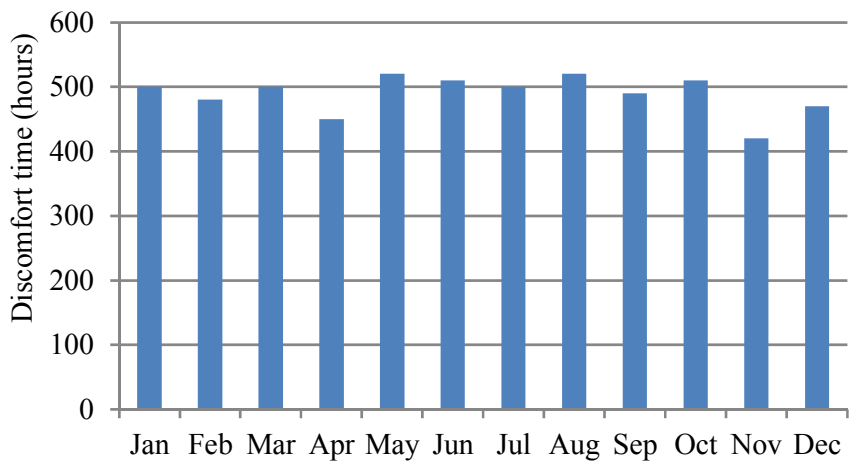

Figure 5: Calculation of hours of thermal discomfort by Autodesk Ecotect Analysis.

According to the climatic conditions, the discomfort time occurs during working hours (8 a.m. and 6 p.m.).

\subsection{Daylighting}

The illuminance levels were calculated by DesignBuilder and eQUEST. This analysis is based on the simulations for April, considering three times during the 
day (8 a.m., 12 p.m. and 4 p.m.). This month was selected because represents the average conditions of solar radiation in Bucaramanga. Since the behavior of daylight in the building is different in each level, the first and fifth levels are compared. The results of simulations done by DesignBuilder are presented in Table 7.

Table 7: Illumination level in two apartments by Designbuider.

\begin{tabular}{|c|c|c|c|c|c|c|}
\hline \multirow{2}{*}{ Apart } & \multicolumn{3}{|c|}{ Level 1 [lux] } & \multicolumn{3}{c|}{ Level 5 [lux] } \\
\cline { 2 - 7 } & 8 a.m. & 12 p.m. & 4 p.m. & 8 a.m. & 12 p.m. & 4 p.m. \\
\hline 1 & 70 & 249 & 185 & 316 & 301 & 222 \\
\hline 2 & 71 & 253 & 200 & 318 & 287 & 254 \\
\hline 3 & 11 & 219 & 64 & 264 & 252 & 308 \\
\hline 4 & 11 & 212 & 59 & 216 & 236 & 305 \\
\hline 5 & 14 & 225 & 64 & 277 & 272 & 297 \\
\hline 6 & 5 & 205 & 60 & 315 & 278 & 281 \\
\hline Average & 30.3 & 227.2 & 105.3 & 284.3 & 271.0 & 277.8 \\
\hline
\end{tabular}

Obviously, these results verify the influence of the altitude on illuminance because this is higher in apartments located in high levels; daylight is greater in apartments of fifth level than first level because the obstructions decrease at higher altitudes. For this case, the apartments in the last level can achieved the minimum value (300 lux) during the most of the sun-time, while in apartments of first level the situation is contrary.

The variation of illumination in apartments in the same level is due to the orientation. Now, in Fig. 6 the natural illumination behavior in two apartments is shown during 24 hours according to results obtained by eQUEST.

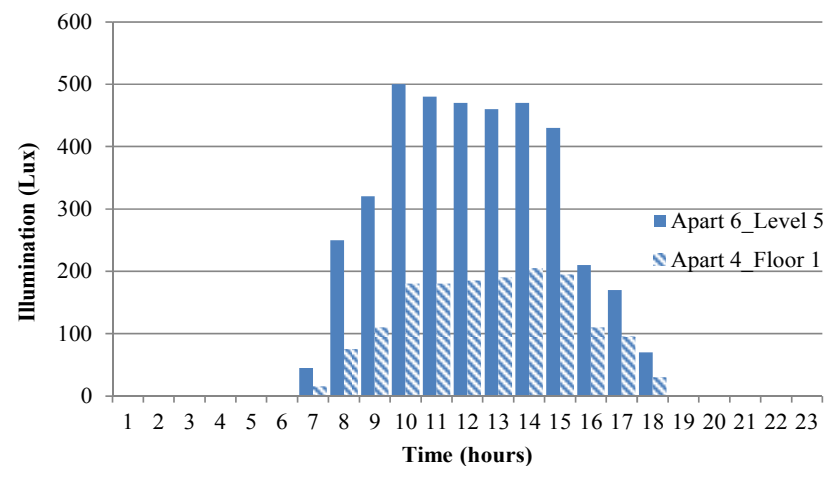

Figure 6: Illumination levels in two apartments according to simulation with eQUEST during a day in April.

Fig. 7 presents the comparison of the results of simulations for two apartments. In general, the level illumination obtained by eQUEST is higher; therefore eQUEST considers lower energy consumption by artificial illumination, such as is shown in Table 8 . 


\subsection{Annual energy consumption}

Table 8 shows the data of annual energy consumption according to the results obtained by simulation tools. This describes the energy demand considering the 30 apartments, whose total area is $1,260 \mathrm{~m}^{2}$.

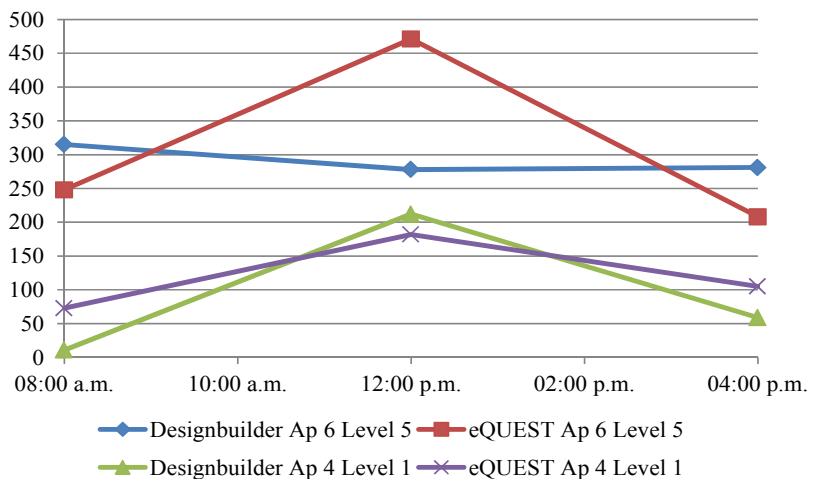

Figure 7: Comparison results in natural illumination between DesignBuilder and eQUEST.

Table 8: Annual energy consumption.

\begin{tabular}{|c|c|c|c|}
\hline Element & DesignBuilder & eQUEST & ECOTECT \\
\hline Illumination & 10,716 & 6,464 & NA \\
\hline Appliances & 28,472 & 29,682 & NA \\
\hline TOTAL & 39,188 & 36,146 & 40,262 \\
\hline Density $\left(\mathrm{kWh} / \mathrm{m}^{2} /\right.$ year) & 31.10 & 28.69 & 31.95 \\
\hline
\end{tabular}

It is possible to see that the energy consumption by appliances in DesignBuilder and eQUEST is similar; however, that is not the case of the illumination, since in the first tool the demand is $10,716 \mathrm{kWh}(27.3 \%)$, while that services in eQUEST is $6,464 \mathrm{kWh}(17.9 \%)$. That can be due to the differences in the approaches in the mathematical models.

The annual energy consumption in each apartment estimated by DesignBuilder and eQUEST is $1306.3 \mathrm{kWh}$ and $1204 \mathrm{kWh}$, respectively, which can be seen in Fig. 8 .

These three tools indicate similar values of the annual energy consumption, therefore it is possible to consider that a good estimation being $31.75 \mathrm{kWh} / \mathrm{m}^{2} /$ year, that is an index of density of energy consumption. Such density is significantly lower in comparison with the north hemisphere case (i.e. $150 \mathrm{kWh} / \mathrm{m}^{2} /$ year), where the energy consumption depends strongly of thermal comfort services, like heating and air conditioning. 


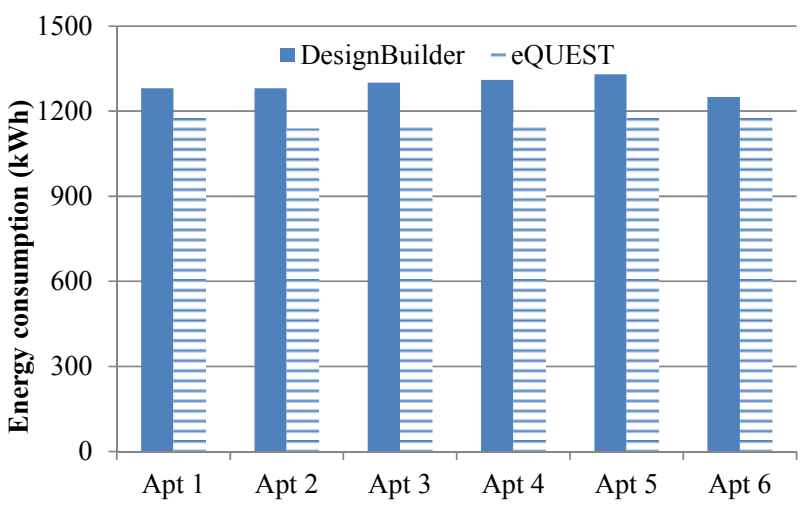

Figure 8: Comparison of annual energy consumption by apartment in a specific level.

\section{Conclusions}

Currently, there are a large number of the energy simulation tools for carrying out energy analysis of buildings, and the trend is growing. Before such offer, it is necessary to do a selection process for establishing a good option according to the needs.

These tools are widely used in temperate zones where the main propose is to establish the thermal performance in heating and cooling conditions due to the season. However, this situation is some different in tropical zones, where the energy consumption by thermal load is lower and the illumination has a significant weight in the bill. For that, studies are required for determining what tools are convenient for analyzing building in these climate conditions, such as in this work has been proposed, from of a methodology for the selection of energy simulation computation tools in three steps: identification of energy building simulation tools, pre-selection of simulation tools and evaluation tools by factors.

In this work were identified three interesting options to be used in tropical zones: DesignBuilder, eQUEST and Autodesk Ecotect Analysis; where the DesignBuilder is a very complete option because allows to carry out analysis in detail with a reasonable cost, and eQUEST has an excellent performance for medium-range energy analysis.

With respect to the energy characteristics of the social dwellings in Colombia, it is possible to see that although these apartments resolve housing need, the thermal comfort levels are not satisfactory, due mainly to climate, small size of the apartments and materials of construction. Fortunately, the Colombian government is aimed to establish guidelines for improving the energy performance of this housing. 


\section{References}

[1] S. K. Constantinos A. Balaras, Kalliopi Droutsa, Elena Dascalaki, "Heating energy consumption and resulting environmental impact of European apartment buildings," ELSEVIER, vol. 37, no. 5, pp. 429-442, 2005.

[2] Colombia. Ministerio de Ambiente Vivienda y Desarrollo Territorial., "Calidad en la Vivienda de Interés Social." AINCOL, Bogotá, Colombia, p. 61, 2011.

[3] S. Attia, J. L. M. Hensen, L. Beltrán, and A. De Herde, "Selection criteria for building performance simulation tools: contrasting architects' and engineers' needs," J. Build. Perform. Simul., vol. 5, no. 3, pp. 155-169, May 2012.

[4] M. N. G. Guillermo Gómez Prada, Jesús Maellas Benito, Borja Plaza Gallardo, "Estado Del Arte De La Modelización Energética De Edificios." Observatorio de la Sostenibilidad en España (OSE), pp. 1-22, 2007.

[5] U.S. Department of Energy, "Building Energy Software Tools Directory," 2014. [Online]. Available: http://apps1.eere.energy.gov/buildings/tools_ directory/

[6] R. L. Mantilla Mejia and M. Millan Martinez, "Computational tools for energy analysis in social dwelling (Herramientas computacionales para análisis energético de viviendas de interés social)," Industrial University of Santander. Degree work advised by MSc. Germán Alfonso Osma Pinto, 2014.

[7] SECOP, "Sistema Electrónico de Contratación Pública," 2014. [Online]. Available: https://www.contratos.gov.co/consultas/inicioConsulta.do

[8] INVISBU, “Altos de Betania," 2014. [Online]. Available: http://www.invisbu.gov.co/nuestra-gestion/programas-y-proyectos/proyecto2-altos-de-betania 